\title{
Attenuation of Oxidative Stress-Induced Osteoblast Apoptosis by Curcumin is Associated with Preservation of Mitochondrial Functions and Increased Akt-GSK3 $\beta$ Signaling
}

\author{
Panpan Dai ${ }^{a}$ Yixin Mao ${ }^{a}$ Xiaoyu Sun ${ }^{a}$ Xumin Li ${ }^{a}$ Ibrahim Muhammad \\ Weiyan Gu,b Dafeng Zhang ${ }^{\mathrm{b}}$ Yu Zhou ${ }^{\mathrm{c}}$ Zhenyu Nic Jianfeng Ma,b \\ Shengbin Huang ${ }^{a, b}$
}

aInstitute of Stomatology, School and Hospital of Stomatology, Wenzhou Medical University, Wenzhou, bDepartment of Prosthodontics, School and Hospital of Stomatology, Wenzhou Medical University, Wenzhou, 'Department of Orthodontics, School and Hospital of Stomatology, Wenzhou Medical University, Wenzhou, China

\section{Key Words}

Osteoblast • Osteoporosis • Oxidative stress $\cdot$ Apoptosis $•$ Mitochondrial function $\cdot$ Reactive oxygen species

\begin{abstract}
Background: Osteoblast apoptosis induced by oxidative stress plays a crucial role in the development and progression of osteoporosis. Curcumin, a natural antioxidant isolated from Curcuma longa, has highly protective effects against osteoporosis. However, the effects of curcumin on oxidative stressinduced osteoblast apoptosis remain unclear. This study aimed to explore the effect of curcumin on hydrogen peroxide $\left(\mathrm{H}_{2} \mathrm{O}_{2}\right)$ induced osteoblast apoptosis and the underlying mechanisms. Methods: An osteoblastic cell line (Saos-2) was exposed to various concentrations of $\mathrm{H}_{2} \mathrm{O}_{2}$ with or without curcumin treatment. Cell viability was evaluated by MTT assays. The apoptosis rate was analyzed by flow cytometry and TUNEL assays. Mitochondrial ROS and membrane potential were determined using a fluorescence microscope. Mitochondrial respiratory enzyme activity was measured using a spectrophotometer. Protein levels were detected by western blotting. Results: Curcumin was cytoprotective because it greatly improved the viability of Saos-2 cells exposed to $\mathrm{H}_{2} \mathrm{O}_{2}$ and attenuated $\mathrm{H}_{2} \mathrm{O}_{2}$-induced apoptosis. Curcumin treatment also preserved the mitochondrial redox potential, decreased the mitochondrial oxidative status, and improved the mitochondrial membrane potential and functions. Furthermore, curcumin treatment markedly increased levels of phosphorylated protein kinase B (Akt) and phosphorylated glycogen synthase kinase-3 $\beta$ (GSK3 $\beta$ ). Conclusion: Curcumin administration ameliorates oxidative stress-induced apoptosis in osteoblasts by preserving mitochondrial functions and activation of Akt-GSK3 $\beta$ signaling. These data provide experimental evidence supporting the clinical use of curcumin for prevention or treatment of osteoporosis.

(C) 2017 The Author(s)

P. Dai and Y. Mao contributed equally to this work.

Jianfeng $\mathrm{Ma}, \mathrm{PhD}$

and Shengbin Huang, PhD.

KARGER
Department of Prosthodontics, and Institute of Stomatology, School and Hospital of Stomatology, School and Hospital of Stomatology, Wenzhou Medical University,

373 Xueyuan West Road, Lucheng District, Wenzhou 325000, (China)

E-Mail dentistmacn@aliyun.com / huangsb003@wmu.edu.cn 
Dai et al.: Curcumin Attenuated Osteoblast Apoptosis via Mitochondrial Function and Akt-GSK3ß Signaling

\section{Introduction}

Osteoporosis is a common systemic skeletal disease characterized by decreased bone mass and architectural deterioration of bone tissues. Recent evidence indicates that oxidative stress (OS), which results from an imbalance of oxidants and antioxidants in favor of the former, is a major factor in the development and progression of osteoporosis [1,2].

Osteoblast apoptosis plays a crucial role in bone development and maintenance, and partly contributes to diseases such as osteoporosis in sex steroid deficiency, glucocorticoid excess, and aging [3]. Many studies have demonstrated that increased OS persists in these pathological conditions, which might contribute to inhibition of osteoblast differentiation [4] and proliferation [5] or induction of cell apoptosis [6, 7]. Thus, alleviation of osteoblast apoptosis caused by OS is very important to prevent or at least delay the loss of bone mass in osteoporosis.

Mitochondria are the primary source of reactive oxygen species (ROS) and the principal sites of ROS-induced damage. Mitochondrial dysfunction essentially influences osteoblasts through the regulation of mitophagy, apoptosis, and mitochondrial DNA damage [8-10]. Improving mitochondrial functions through the application of antioxidants can prevent cytotoxicity and dysfunction in osteoblasts $[9,11]$. Curcumin is a naturally occurring yellow molecule in turmeric, which demonstrates potent antioxidant and anti-inflammatory properties $[12,13]$. It has been found to protect against intracellular ROS and demonstrates a free radical-scavenging activity [14]. Most importantly, curcumin has attracted considerable interest because of its preventative effects on processes related to osteoporosis. Numerous in vitro studies indicate that curcumin inhibits osteoclast proliferation and differentiation by suppressing ROS generation, and thus prevents bone loss in rodent models of postmenopausal osteoporosis [15-17], diabetes [18], and Alzheimer's disease [19]. Moreover, curcumin shows similar benefits in rodent models of hindlimb suspension [20] and spinal cord injury [21]. These findings suggest that curcumin affects the activity and number of osteoclasts, rather than osteoblasts, in the progression of bone loss associated with various pathological processes. Nonetheless, some studies have reported that high doses $(>10 \mu \mathrm{M})$ of curcumin inhibit proliferation of rat calvarial osteoblasts and human osteoblast cell death [22-24]. $\mathrm{Gu}$ et al. demonstrated that $10 \mu \mathrm{M}$ curcumin promotes osteoblastic differentiation of rat mesenchymal stem cells by upregulation of HO-1 [25]. Moreover, Xin et al. showed that 4 $\mu \mathrm{M}$ curcumin increases osteoblastic differentiation of MC3T3-E1 cells exposed to modeled microgravity [20]. The divergence among these results was probably related to differences in the curcumin dosage, application duration, and modes of administration. Some studies indicate that curcumin treatment attenuates pathological conditions through activation of prosurvival signaling pathways [26, 27]. To a large extent, these protective effects of curcumin have been attributed to its strong activity against mitochondrial dysfunction $[28,29]$. Because of its potent antioxidant properties and an anti-apoptotic activity in noncancerous cells, we hypothesized that curcumin might effectively protect osteoblasts from oxidative damage.

Protein kinase B (Akt) is a serine/threonine protein kinase that functions as a critical regulator of cell survival and proliferation. Activated Akt inhibits glycogen synthase kinase $3 \beta$ (GSK3 $\beta$ ) by phosphorylation. GSK3 $\beta$ mediates OS-induced apoptosis by activating Caspase- 3 and promoting cytochrome c release from mitochondria [30, 31]. However, the role of AktGSK3 $\beta$ in regulating OS-induced osteoblast apoptosis is unknown. Furthermore, studies have indicated that curcumin exerts a protective effect against apoptosis via the phosphoinositide 3-kinase (PI3K)/Akt signaling pathway $[32,33]$. However, whether curcumin treatment promotes osteoblast survival through prevention of OS-induced mitochondrial dysfunction and activation of Akt-GSK3 $\beta$ signaling remains unclear.

Therefore, we examined the effects of curcumin on hydrogen peroxide $\left(\mathrm{H}_{2} \mathrm{O}_{2}\right)$-induced apoptosis of osteoblasts and its potential mechanisms. Our findings might provide new insights into the role of curcumin in OS-induced osteoblast apoptosis, thereby highlighting its potential therapeutic application for osteoporosis. 


\section{Cellular Physiology Cell Physiol Biochem 2017;41:661-677

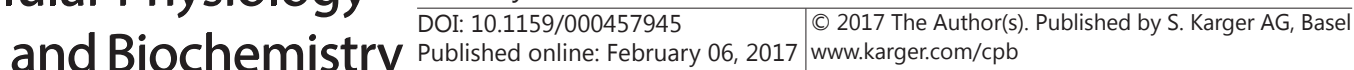

Dai et al.: Curcumin Attenuated Osteoblast Apoptosis via Mitochondrial Function and

Akt-GSK3 $\beta$ Signaling

\section{Materials and Methods}

Reagents

Cell culture medium and supplements were purchased from Life Technologies (Grand Island, NY, USA). Anti-phospho-Akt (S473), anti-Akt, anti-phospho-GSK3 $\beta$ (Ser9), anti-GSK3 $\beta$, anti-Bcl-2, anti-Bax, anti-Caspase- 3 and anti- $\beta$-actin antibodies were obtained from Cell Signaling Technology (Beverly, MA, USA). Chamber slides, and goat anti-rabbit and anti-mouse secondary antibodies were from Thermo Fisher Scientific (Waltham, MA, USA). MitoSOX Red (Molecular Probes, USA), tetramethylrhodamine methylester (TMRM) (Molecular Probes), and Mitotracker Green (MTGreen, Molecular Probes) were from Life Technologies. A terminal deoxynucleotidyl transferase (TdT)-mediated deoxyuridine triphosphate (dUTP) nick end labeling (TUNEL) kit was from Roche (Mannheim, Germany). Curcumin, 3-(4,5-dimethylthiazol2-yl)-2,5-diphenyltetrazolium bromide (MTT), an Annexin V-fluorescein isothiocyanate (FITC) apoptosis detection kit, manganese-3-methoxy N, N'-bis (salicylidene) ethylenediamine chloride (EUK134), 4-benzyl2-methyl-1,2,4-thiadiazolidine-3,5-dione (TDZD-8), $\mathrm{H}_{2} \mathrm{O}_{2}$, and LY294002 were from Sigma Aldrich (St. Louis, MO, USA).

\section{Cell Culture}

The human osteoblastic cell line (Saos-2) used in this study was obtained from the American Type Culture Collection (Manassas, VA, USA). Cells were maintained in McCoy's 5a modified medium supplemented with $10 \%$ fetal bovine serum and antibiotics (100 IU/ml penicillin $\mathrm{G}$ and $100 \mathrm{ng} / \mathrm{ml}$ streptomycin) in a humidified incubator at $37{ }^{\circ} \mathrm{C}$ with $5 \% \mathrm{CO}_{2}$. The culture medium was replenished twice per week.

Cell Treatments

Test compounds were prepared as stock solutions and diluted to the desired final concentrations immediately before use. The working concentrations of the compounds were as follows: $\mathrm{H}_{2} \mathrm{O}_{2}(100,200$, and $250 \mu \mathrm{M})$, EUK134 $(10 \mu \mathrm{M})$, TDZD-8 (5 $\mu \mathrm{M})$, LY294002 (10 $\mu \mathrm{M})$, and curcumin $(10,20,30,40$, and $50 \mu \mathrm{M})$. The final concentration of the vehicle, dimethyl sulfoxide (DMSO), was less than $0.5 \%$ in all experiments. Cells were treated with or without $\mathrm{H}_{2} \mathrm{O}_{2}$ and the indicated test compounds for various times, according to the experimental protocol.

\section{Cell Viability}

Osteoblasts were seeded in 96-well plates $\left(1 \times 10^{4}\right.$ cells/well) and cultured under various conditions, as indicated for each experiment. Briefly, osteoblasts were washed twice with phosphate buffered saline (PBS) and incubated in $100 \mu \mathrm{l} /$ well serum-free medium supplemented with $10 \mu \mathrm{l}$ MTT solution $(5 \mathrm{mg} / \mathrm{ml})$ at $37^{\circ} \mathrm{C}$. After $4 \mathrm{~h}$, the supernatant was removed, and the formazan crystals were dissolved by incubation with $150 \mu \mathrm{l} /$ well DMSO for $20 \mathrm{~min}$. The plates were then agitated for $15 \mathrm{~s}$ and absorbance at $570 \mathrm{~nm}$ was measured in a microplate reader.

Measurement of Apoptosis by Flow Cytometry and TUNEL assays

Apoptosis of osteoblasts was detected by Annexin-V labeled with FITC. Propidium iodide (PI; $1 \mu \mathrm{g} /$ $\mathrm{ml}$ ) was used to determine cell necrosis. After exposure to various experimental conditions, cells were trypsinized and labeled with fluorochromes at $37^{\circ} \mathrm{C}$, and then cytofluorometric analysis was performed with a FACScan (Becton Dickinson, NY, USA).

Apoptosis was also evaluated by the TUNEL method. For the TUNEL assays, cells grown on a coverslip were pretreated with or without compounds in the presence of $\mathrm{H}_{2} \mathrm{O}_{2}(0.25 \mathrm{mM})$ for 6 hours. After treatment, the cells were washed with PBS, fixed in $4 \%$ paraformaldehyde/PBS, and permeabilized with $0.2 \%$ Triton $\mathrm{X}-100$ in citrate buffer. Samples were incubated with TdT and fluorescein-labeled dUTP, counterstained with 4', 6-diamidino-2-phenylindole (DAPI), and then observed under a fluorescence microscope (Leica TCS SPE, Germany). Percentages of apoptotic cells were estimated by counting 300 cells in random fields.

\section{Western Blot Analyses}

After the indicated treatments, osteoblasts were collected and lysed in cell lysis buffer (Cell Signaling Technology, Beverly, MA, USA). Protein concentrations were determined using a Bradford protein assay kit (Thermo Fisher Scientific). Proteins were separated by electrophoresis and transferred to a polyvinylidene difluoride membrane. Anti-phospho-Akt (1:2000), anti-Akt (1:2000), anti-phospho-GSK3 (1:2000), 


\section{Cellular Physiology Cell Physiol Biochem 2017;41:661-677 \\ \begin{tabular}{l|l|l} 
and Biochemistry & DOI: 10.1159/000457945 & $\begin{array}{l}\text { C) } 2017 \text { The Author(s). Published by S. Karger AG, Basel } \\
\text { www.karger.com/cpb }\end{array}$
\end{tabular}}

Dai et al.: Curcumin Attenuated Osteoblast Apoptosis via Mitochondrial Function and

Akt-GSK3 $\beta$ Signaling

anti-GSK3 $\beta$ (1:2000), anti-Bcl-2 (1:2000), anti-Bax(1:2000), anti-Caspase-3 (1:1000), and anti- $\beta$-actin antibodies were used as primary antibodies. Proteins bound by primary antibodies were visualized with an appropriate secondary antibody (1:5000), followed by addition of an enhanced chemiluminescence substrate (Thermo Fisher Scientific). The protein bands were detected using the Bio-Rad imaging system (Bio-Rad, Hercules, CA, USA) and quantified using NIH ImageJ software (available in the public domain).

Measurements of Mitochondrial Respiratory Enzyme Activity

Mitochondrial respiration complex activity was measured in osteoblast lysates as described previously $[34,35]$. Briefly, osteoblasts in 6-well plates were washed with ice-cold PBS, harvested, centrifuged, and resuspended in $50 \mu$ isolation buffer $\left(225 \mathrm{mM} \mathrm{D}\right.$-mannitol, $75 \mathrm{mM}$ sucrose, $2 \mathrm{mM} \mathrm{K}_{2} \mathrm{HPO}_{4}$, and $5 \mathrm{mM} \mathrm{HEPES}$, $\mathrm{pH}$ 7.2). Aliquots (10-50 $\mu \mathrm{g}$ protein) of mitochondrial membrane fractions were then assayed for respiratory complex activities. In our previous report [36], $\mathrm{H}_{2} \mathrm{O}_{2}$ significantly decreased ubiquinol cytochrome $\mathrm{C}$ oxidoreductase (complex III) and coenzyme Q ( $\mathrm{CoQ})$ activities in osteoblasts. Therefore, we only measured the activities of these respiratory chain components.

Functional Imaging Assays

Osteoblasts were seeded in chamber slides at $1 \times 10^{4}$ cells/well. Cells were treated with $\mathrm{H}_{2} \mathrm{O}_{2}$ and other test compounds for $1 \mathrm{~h}$. Then, the cells were incubated in fresh culture medium containing $2.5 \mu \mathrm{M}$ MitoSOX for $30 \mathrm{~min}$. To assess the mitochondrial membrane potential, cells were co-stained with MT Green (100 nM) and TMRM (100 nM) for $30 \mathrm{~min}$, according to our previous study [37].

Images were captured under the fluorescence microscope. Excitation wavelengths were $543 \mathrm{~nm}$ for MitoSOX and TMRM and $488 \mathrm{~nm}$ for MT Green. Post-acquisition processing was performed with NIH ImageJ software to measure and quantify fluorescence signals. Mitochondrial fluorescence intensities were quantified by an investigator blinded to the experimental groups. More than 100 clearly identifiable mitochondria in 10-15 randomly selected cells per experiment were measured in three independent experiments.

\section{Data Analysis}

Data are presented as means \pm standard error of the mean. Statistical analysis was performed using Statview software (Version 5.0.1, SAS Institute, USA). Group mean differences were assessed by the Student's t-test for two comparisons or one-way analysis of variance with a Bonferroni/Dunn post-hoc test for multiple comparisons. $P<0.05$ was considered to be significant.

\section{Results}

$\mathrm{H}_{2} \mathrm{O}_{2}$-induced Apoptosis and Mitochondrial Dysfunction in Osteoblasts

To determine the effect of ROS on survival of Saos- 2 osteoblasts, we performed MTT cell viability assays. After $\mathrm{H}_{2} \mathrm{O}_{2}$ treatment, the number of viable cells decreased in a time and dose-dependent manner (Fig. 1A). Flow cytometric analysis showed a dose-dependent increase in the incidence of apoptosis. Although early apoptosis was detected after $0.1 \mathrm{mM}$ $\mathrm{H}_{2} \mathrm{O}_{2}$ treatment, higher concentrations of $\mathrm{H}_{2} \mathrm{O}_{2}$ induced late apoptosis and a slight increase in necrosis (Fig. 1B, C). These proapoptotic effects were confirmed by TUNEL staining (Fig. 1D, E).

Bcl-2 family proteins, including Bcl-2 and Bax, play important roles in initiating the mitochondrial death cascade. The role of apoptosis-related Bcl-2 gene expression in $\mathrm{H}_{2} \mathrm{O}_{2}$ induced osteoblast apoptosis was examined by immunoblot analyses (Fig. 1F, G). Compared with the control group, $\mathrm{H}_{2} \mathrm{O}_{2}$ significantly decreased the expression of $\mathrm{Bcl}-2$, while no significant differences were observed in Bax expression (Fig. 1F and I). In addition, Caspase-3 cleavage is a key and irreversible event in the progression of apoptosis. Exposure of Saos-2 cells to $\mathrm{H}_{2} \mathrm{O}_{2}$ caused an increase in the expression of cleaved Caspase- 3 (Fig. $1 \mathrm{~F}$ and $\mathrm{H}$ ). These results indicate that $\mathrm{H}_{2} \mathrm{O}_{2}$-induced cell death occurs primarily through apoptosis in Saos-2 cells.

Mitochondrial dysfunction plays a cardinal role in OS-induced dysfunction of cell proliferation, differentiation and survival in osteoblasts. Consistent with our previous study 
Dai et al.: Curcumin Attenuated Osteoblast Apoptosis via Mitochondrial Function and Akt-GSK3 $\beta$ Signaling

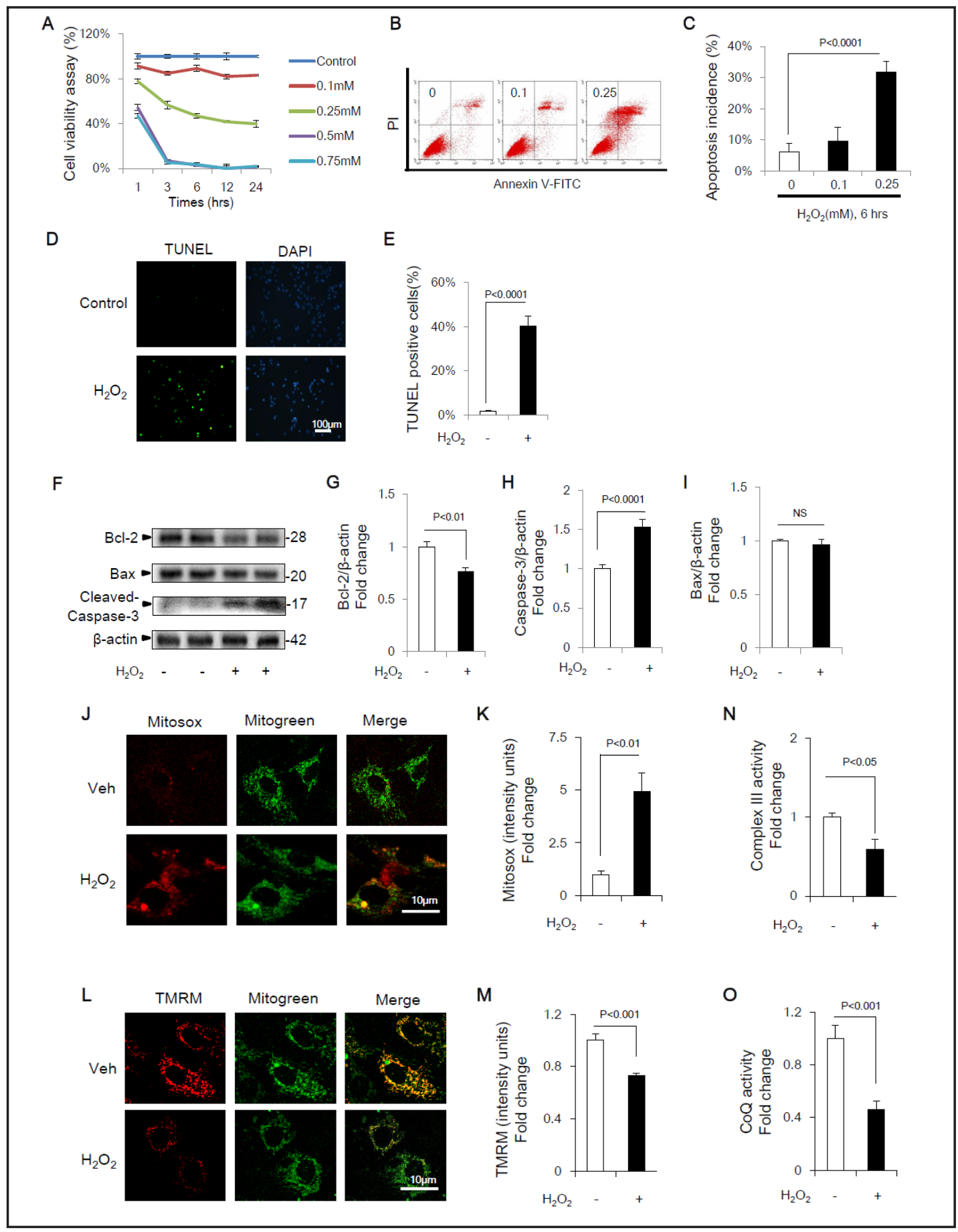

Fig. 1. $\mathrm{H}_{2} \mathrm{O}_{2}$-induced apoptosis in osteoblasts. (A) Cell viability was determined by MTT reduction in osteoblasts in the presence of $\mathrm{H}_{2} \mathrm{O}_{2}$ Error bars indicate SEM (n=6). (B) and (C) Flow cytometric quantification of apoptosis. Error bars indicate SEM (n=6). (D) and (E) TUNEL staining and assay. Error bars indicate SEM $(n=300)$. (F) Representative immunoreactive bands for Bcl-2, Bax and Caspsae-3 in osteoblasts in the presence of $\mathrm{H}_{2} \mathrm{O}_{2}$. Quantification of immunoreactive bands for Bcl-2 (G), Bax (H) and Caspsae-3 (I) relative to $\beta$-actin. Error bars indicate SEM $(n=6) . \mathrm{H}_{2} \mathrm{O}_{2}$-induced mitochondrial dysfunction in osteoblasts. Representative images showing MitoSOX staining (J) and quantification (K) in the indicated groups. Representative images with TMRM staining (L) and quantification (M) in the indicated groups. Complex III activity (N) and $\mathrm{CcO}$ activity $(0)$ in the indicated groups. Error bars indicate SEM $(n=15)$.

\section{KARGER}


Dai et al.: Curcumin Attenuated Osteoblast Apoptosis via Mitochondrial Function and Akt-GSK3ß Signaling

[38], the staining intensity of MitoSOX, an indicator of mitochondrial ROS, was significantly increased in osteoblasts treated with $\mathrm{H}_{2} \mathrm{O}_{2}$ (Fig. 1J, K). The mitochondrial membrane potential, as indicated by the fluorescent dye TMRM, was significantly decreased in cells treated with $\mathrm{H}_{2} \mathrm{O}_{2}$ (Fig. 1L, M).

Oxidative phosphorylation enzyme complexes are essential for mitochondrial functions. Therefore, key enzymes associated with the respiratory chain were evaluated in this study. Cells treated with $\mathrm{H}_{2} \mathrm{O}_{2}$ had significantly decreased complex III (Fig. 1N) and CoQ (Fig. 10) activities compared with control cells.

Curcumin attenuates $\mathrm{H}_{2} \mathrm{O}_{2}$-induced Apoptosis and Mitochondrial Dysfunction in Osteoblasts

Although curcumin has shown promising anti-apoptotic effects on various types of non-cancerous cells, its effects on OS-induced osteoblast apoptosis have been unknown. To determine whether curcumin protected osteoblasts from oxidative stress, we treated Saos2 cells with various concentrations of curcumin prior to $\mathrm{H}_{2} \mathrm{O}_{2}$ exposure. As shown in Fig. $2 \mathrm{~A}$, curcumin treatment $(50 \mu \mathrm{M}, 9 \mathrm{~h})$ was not cytotoxic in Saos-2 cells, and the reduced cell viability was significantly rescued by curcumin in a dose-dependent manner $(P<0.001)$. However, no obvious differences were observed at concentrations of $>20 \mu \mathrm{M}$. Thus, we chose $20 \mu \mathrm{M}$ as our experimental concentration. Moreover, cell apoptosis induced by $\mathrm{H}_{2} \mathrm{O}_{2}$ was significantly decreased by curcumin pretreatment $(P<0.05)$ (Fig. 2B, C). As expected, curcumin preconditioning ameliorated $\mathrm{H}_{2} \mathrm{O}_{2}$-induced suppression of $\mathrm{Bcl}-2$ protein synthesis and reduced cleavage of Caspase-3 (Fig. 2D-F). These data indicate that curcumin attenuates $\mathrm{H}_{2} \mathrm{O}_{2}$-induced apoptosis in osteoblasts.

Because mitochondria are a primary source of ROS generation and ROS accumulation affects mitochondrial functions, we determined whether mitochondrial ROS generation correlated with mitochondrial dysfunction. Indeed, the MitoSOX staining intensity was significantly increased in osteoblasts treated with $\mathrm{H}_{2} \mathrm{O}_{2}$. Curcumin treatment significantly attenuated mitochondrial ROS levels, as shown by a reduced MitoSOX intensity (Fig. 2G, H).

We characterized mitochondrial functions by evaluating the membrane potential and key enzymes of the respiratory chain in osteoblasts incubated under various conditions. Compared with cells receiving only $\mathrm{H}_{2} \mathrm{O}_{2}$, osteoblasts co-treated with curcumin had significantly increased membrane potentials (Fig. 2I, J) and activities of complex III (Fig. 2K) and CoQ (Fig. 2L).

Synthetic Antioxidant Compound EUK134 prevents $\mathrm{H}_{2} \mathrm{O}_{2}$-induced Apoptosis and Mitochondrial Dysfunction in Osteoblasts

Because mitochondrial OS was implicated in causing osteoblast dysfunction, we examined whether antioxidant treatments could prevent the osteoblast dysfunction induced by $\mathrm{H}_{2} \mathrm{O}_{2}$. As shown in Fig. 3A, osteoblasts treated with EUK134 and $\mathrm{H}_{2} \mathrm{O}_{2}$ had improved cell viability compared with those treated with $\mathrm{H}_{2} \mathrm{O}_{2}$ only. EUK134 treatment significantly inhibited cell apoptosis induced by $\mathrm{H}_{2} \mathrm{O}_{2}$, as shown by TUNEL staining (Fig. 3B, C). In addition, consistent with curcumin treatment, EUK134 treatment markedly recovered Bcl-2 protein expression and decreased cleaved Caspase-3 (Fig. 3D-F) in the cells compared with the $\mathrm{H}_{2} \mathrm{O}_{2}$-treated group.

As shown in Fig. 3, EUK134 treatment significantly suppressed mitochondrial ROS levels (Fig. 3G, H) and increased the mitochondrial membrane potential (Fig. 3I, J). Consistent with these results, addition of EUK134 enhanced complex III (Fig. 3K) and CoQ (Fig. 3L) activities compared with cells receiving $\mathrm{H}_{2} \mathrm{O}_{2}$ alone. These results indicate that EUK134 prevents mitochondrial abnormalities in osteoblasts subjected to OS.

Akt-GSK3 $\beta$ Signaling is involved in $\mathrm{H}_{2} \mathrm{O}_{2}$-induced Apoptosis of Osteoblasts

The Akt-GSK3 $\beta$ signaling pathway is involved in OS-induced cell apoptosis [34]. To determine whether this pathway is involved in $\mathrm{H}_{2} \mathrm{O}_{2}$-induced osteoblast apoptosis, we analyzed phosphorylation of Akt and GSK3 $\beta$ by immunoblotting. Compared with untreated cells, osteoblasts treated with $\mathrm{H}_{2} \mathrm{O}_{2}$ had significantly less phosphorylated Akt (0.5-fold 
Dai et al.: Curcumin Attenuated Osteoblast Apoptosis via Mitochondrial Function and Akt-GSK3 $\beta$ Signaling

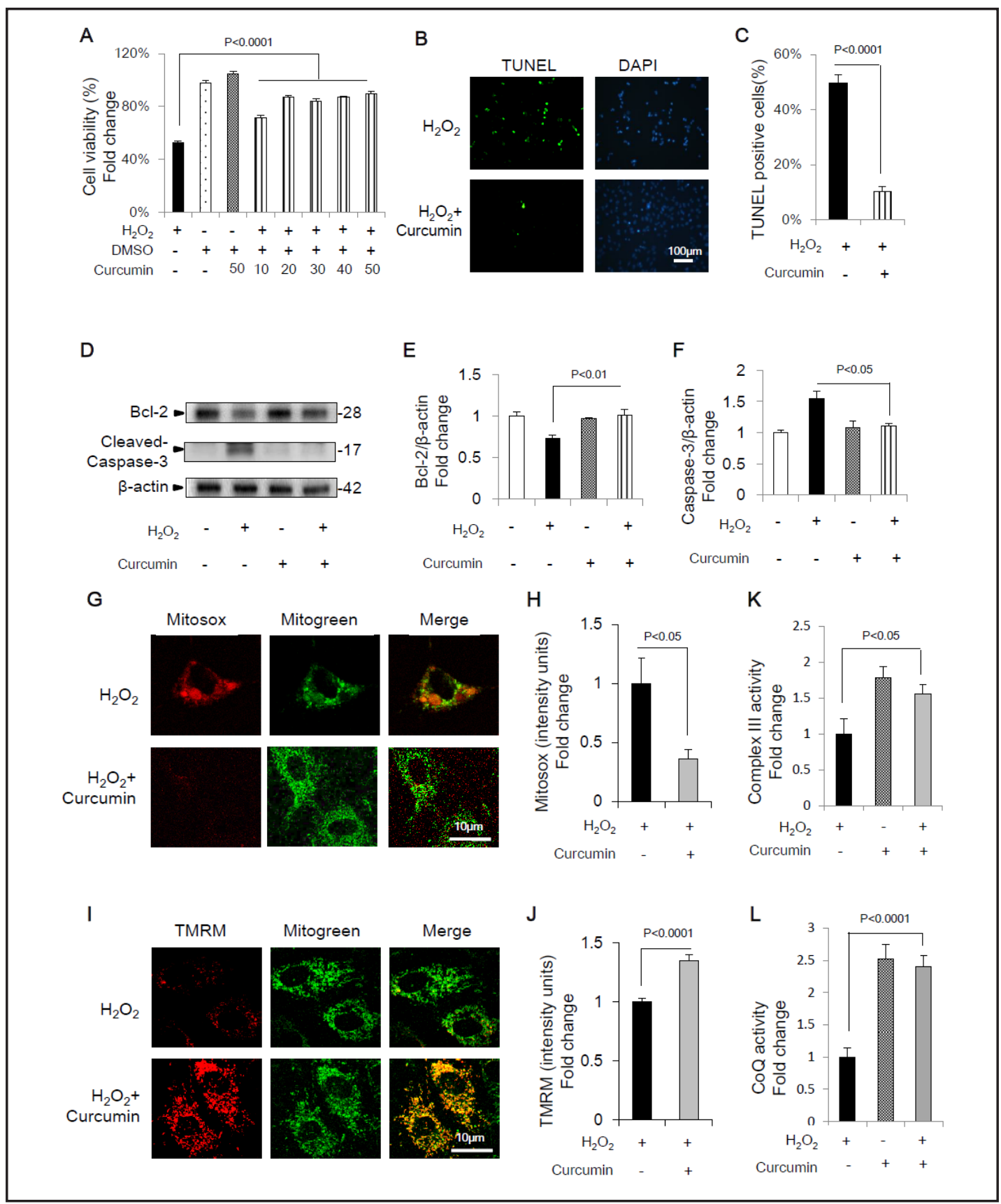

Fig. 2. Curcumin attenuated $\mathrm{H}_{2} \mathrm{O}_{2}$-induced apoptosis in osteoblasts. (A) Cell viability determined by MTT reduction in osteoblasts in the presence of $\mathrm{H}_{2} \mathrm{O}_{2}$ with or without curcumin. Error bars indicate SEM $(n=6)$. (B) TUNEL staining and (C) assay after curcumin treatment. Error bars indicate SEM ( $n=300)$. (D) Representative immunoreactive bands for Bcl-2 and Caspsae-3 in osteoblasts with $(+)$ or without (-) curcumin treatment in the presence of $\mathrm{H}_{2} \mathrm{O}_{2}(+)$ or culture medium (-). Quantification of immunoreactive bands for Bcl-2 (E) and Caspsae-3 (F) relative to $\beta$-actin. Error bars indicate SEM (n=6). Curcumin attenuated $\mathrm{H}_{2} \mathrm{O}_{2}$-induced mitochondrial dysfunction in osteoblasts. Representative images showing MitoSOX staining (G) and quantification $(\mathrm{H})$ in the indicated groups. Representative images showing TMRM staining (I) and quantification (J) in the indicated groups. Complex III activity (K) and CoQ activity (L) in the indicated groups. Error bars indicate SEM $(\mathrm{n}=15)$.

decrease) (Fig. 4A, B) and GSK3 $\beta$ (0.1-fold decrease) (Fig. 4C, D), while total levels of Akt and GSK3 $\beta$ were unchanged. Moreover, treatment with TDZD-8, a pharmaceutical inhibitor 
Dai et al.: Curcumin Attenuated Osteoblast Apoptosis via Mitochondrial Function and Akt-GSK3 $\beta$ Signaling

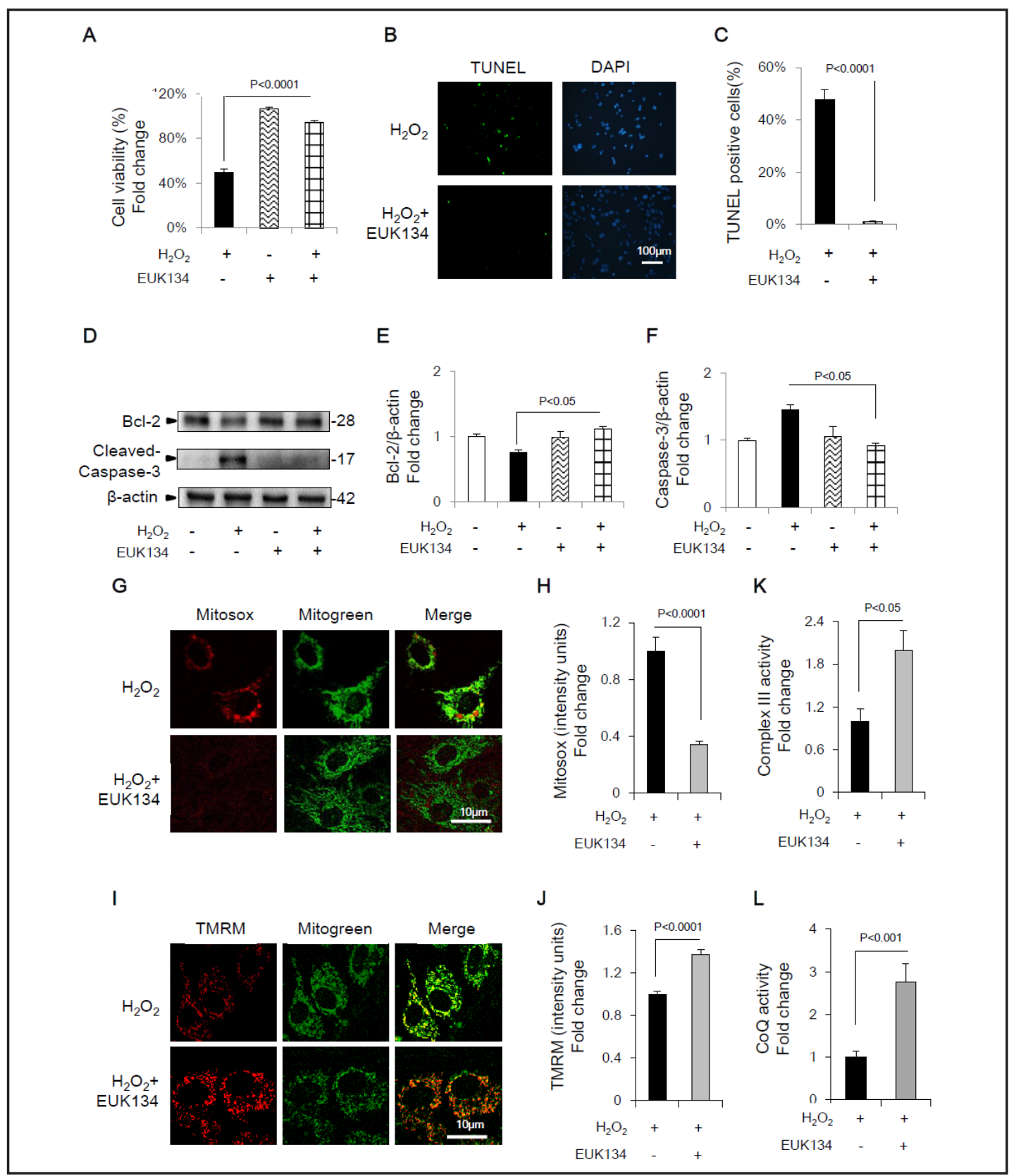

Fig. 3. The synthetic antioxidant EUK134 attenuated $\mathrm{H}_{2} \mathrm{O}_{2}$-induced apoptosis in osteoblasts. (A) Cell viability determined by MTT reduction in osteoblasts in the presence of $\mathrm{H}_{2} \mathrm{O}_{2}$ with or without EUK134. Error bars indicate SEM $(n=6)$. (B) TUNEL staining and (C) assay after EUK134 treatment. Error bars indicate SEM ( $\mathrm{n}=300)$. (D) Representative immunoreactive bands for Bcl-2 and Caspsae-3 in osteoblast with (+) or without (-) EUK134 treatment in the presence of $\mathrm{H}_{2} \mathrm{O}_{2}(+)$ or culture medium (-). Quantification of immunoreactive bands for Bcl-2 (E) and Caspsae-3 (F) relative to $\beta$-actin. EUK134 attenuated $\mathrm{H}_{2} \mathrm{O}_{2}$-induced mitochondrial dysfunction in osteoblasts. Error bars indicate SEM (n=6). Representative images showing MitoSOX staining $(\mathrm{G})$ and quantification $(\mathrm{H})$ in the indicated groups. Representative images showing TMRM staining (I) and quantification (J) in the indicated groups. Complex III activity (K) and CoQ activity (L) in the indicated groups. Error bars indicate SEM (n=15).

of GSK3 $\beta$ (Fig. 4G), significantly inhibited the $\mathrm{H}_{2} \mathrm{O}_{2}$-induced cytotoxicity and apoptosis based on MTT assays results (Fig. 4H) and TUNEL staining (Fig. 4K, L), respectively. Furthermore,

\section{KARGER}


Dai et al.: Curcumin Attenuated Osteoblast Apoptosis via Mitochondrial Function and Akt-GSK3ß Signaling

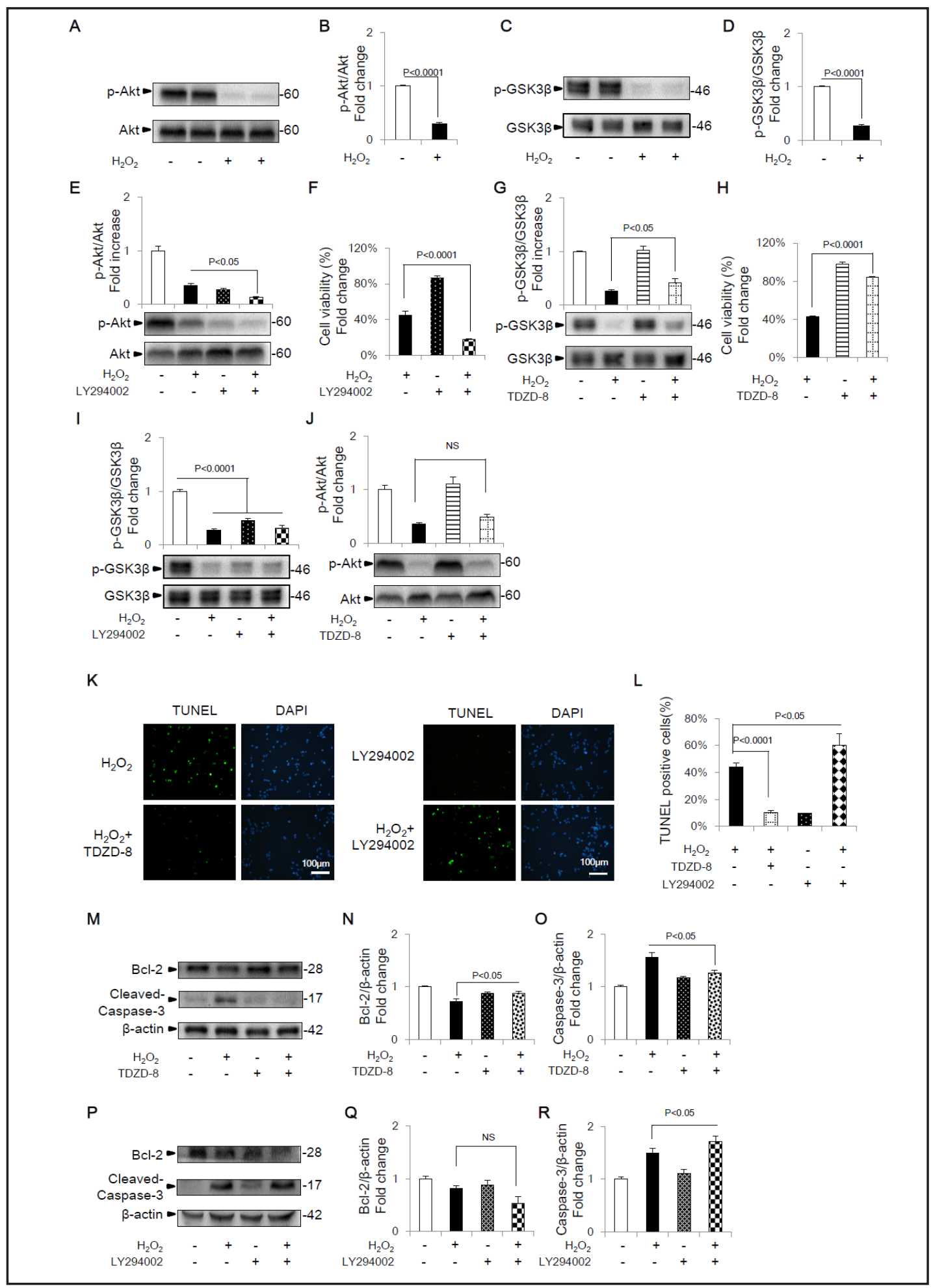

Fig. 4. Involvement of Akt-GSK3 $\beta$ signaling in $\mathrm{H}_{2} \mathrm{O}_{2}$-induced apoptosis in osteoblasts. Representative immunoblots of phospho-Akt (p-Akt) and total Akt (Akt) (A), phospho-GSK3 $\beta$ (p-GSK3 $\beta$ ) and total GSK3 $\beta$ (GS$\mathrm{K} 3 \beta$ ) (C) in osteoblast in the presence of $\mathrm{H}_{2} \mathrm{O}_{2}$. Quantification of immunoreactive bands for p-Akt relative to Akt (B) and p-GSK3 $\beta$ relative to GSK3 $\beta$ (D) in osteoblasts, after the indicated treatments, using NIH Image J software; Densitometry of immunoreactive bands for p-Akt and Akt (E), p-GSK3 $\beta$ and GSK3 $\beta$ (I) in osteoblasts with (+) or without (-) LY294002 treatment in the presence of $\mathrm{H}_{2} \mathrm{O}_{2}(+)$ or culture medium (-). Repre-

\section{KARGER}




\section{Cellular Physiology Cell Physiol Biochem 2017;41:661-677

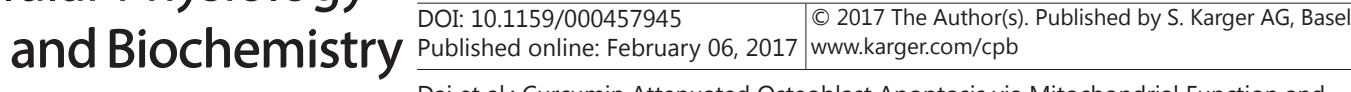

Dai et al.: Curcumin Attenuated Osteoblast Apoptosis via Mitochondrial Function and Akt-GSK3 $\beta$ Signaling

sentative immunoblots are shown at the bottom. (F) Cell viability determined by MTT reduction in osteoblasts with (+) or without (-) LY294002 treatment in the presence of $\mathrm{H}_{2} \mathrm{O}_{2}(+)$. Representative immunoreactive bands and relative levels of p-GSK3 $\beta$ and GSK3 $\beta(\mathrm{G})$, p-Akt and Akt (J) in osteoblasts with (+) or without $(-)$ TDZD-8 treatment in the presence of $\mathrm{H}_{2} \mathrm{O}_{2}(+)$ or culture medium (-), Representative immunoblots are shown at the bottom. (H) Cell viability determined by MTT reduction in osteoblasts with (+) or without (-) TDZD-8 treatment in the presence of $\mathrm{H}_{2} \mathrm{O}_{2}(+)$. Error bars indicate SEM (n=6). (K) TUNEL staining and (L) assay in the indicated groups. Error bars indicate SEM (n=300). (M) Representative immunoreactive bands for Bcl-2 and Caspsae-3 in osteoblasts with (+) or without (-) TDZD-8 treatment in the presence of $\mathrm{H}_{2} \mathrm{O}_{2}$ $(+)$ or culture medium (-). Quantification of immunoreactive bands for Bcl-2 (N) and Caspsae-3 (O) relative to $\beta$-actin. (P) Representative immunoblots of Bcl-2 and Caspsae-3 in osteoblasts with (+) or without (-) LY294002 treatment in the presence of $\mathrm{H}_{2} \mathrm{O}_{2}(+)$ or culture medium (-). (Q-R) Quantification of immunoreactive bands for Bcl-2 and Caspsae- 3 relative to $\beta$-actin in osteoblast. Error bars indicate SEM $(n=6)$.

TDZD-8 preconditioning increased Bcl-2 protein expression and decreased cleaved Caspase-3 (Fig. 4M-0). In contrast, treatment with LY294002, a PI3K inhibitor, decreased the expression of p-Akt (Fig. 4E) and significantly increased the percentage of apoptotic cells in the control group not subjected to OS (Fig. 4K, L). Consistently, western blot analysis revealed that cells incubated with $\mathrm{LY} 294002$ and $\mathrm{H}_{2} \mathrm{O}_{2}$ showed further increased expression of cleaved Caspase-3 (Fig. 4P and R) compared with $\mathrm{H}_{2} \mathrm{O}_{2}$ only, although the change in $\mathrm{Bcl}-2$ expression had no statistical significance (Fig. 4P, Q). Moreover, it inhibited Akt phosphorylation (Fig. 4E, F) and amplified the effect of $\mathrm{H}_{2} \mathrm{O}_{2}$ on induction of apoptosis in osteoblasts (Fig. 4K, L). Conversely, LY294002 treatment significantly decreased the expression of phosphorylated GSK3 $\beta$ (Fig. 4I), whereas TDZD-8 did not affect Akt expression (Fig. 4J), which further supports that Akt regulates phosphorylation of GSK-3 $\beta$. Taken together, these data demonstrate that AktGSK3 $\beta$ signaling is involved in $\mathrm{H}_{2} \mathrm{O}_{2}$-induced apoptosis of osteoblasts.

Curcumin attenuates $\mathrm{H}_{2} \mathrm{O}_{2}$-induced Apoptosis in Osteoblasts through Akt-GSK3 $\beta$

To gain an insight into the mechanism of the preventative effects of curcumin on $\mathrm{H}_{2} \mathrm{O}_{2}$-induced osteoblast apoptosis, the Akt-GSK3 $\beta$ signaling pathway was analyzed by immunoblotting. Interestingly, addition of curcumin or EUK134 resulted in significantly increased levels of p-Akt (Fig. 5A and C) and p-GSK3 $\beta$ (Fig. 5B and D) during $\mathrm{H}_{2} \mathrm{O}_{2}$-induced apoptosis of osteoblasts. However, the anti-apoptotic effect of curcumin was largely abolished by administration of LY294002 (Fig. 5G-K). This result suggests that curcumin treatment is sufficient to promote Akt activation and inhibit GSK3 $\beta$ during OS.

Relationship between the Akt-GSK3 $\beta$ Signaling Pathway and Mitochondrial Dysfunction in OS-induced Osteoblast Apoptosis

Because Akt-GSK3 $\beta$ signaling is known to function as a prosurvival signal, whether mitochondrial dysfunction is related to Akt-GSK3 $\beta$ signaling pathway was determined in the OS-induced osteoblastic apoptosis model. As expected, the results showed that TDZD-8 significantly attenuated mitochondrial ROS levels (Fig. 6A, B) and increased the mitochondrial membrane potential (Fig. 6C, D) and activities of complex III (Fig. 6E) and CoQ (Fig. 6F), which were impaired by OS. However, these mitochondrial dysfunction indexes were further improved by LY294002 cotreatment with $\mathrm{H}_{2} \mathrm{O}_{2}$, although only a significant difference was observed in the mitochondrial membrane potential (Fig. 6G-L).

\section{Discussion}

Several lines of evidence demonstrate the involvement of increased OS in osteoporosis caused by aging and estrogen deficiency [39]. Moreover, osteoblast apoptosis induced by OS is critical for the development of osteoporosis [3]. In our study, we found that administration 
Dai et al.: Curcumin Attenuated Osteoblast Apoptosis via Mitochondrial Function and Akt-GSK3 $\beta$ Signaling

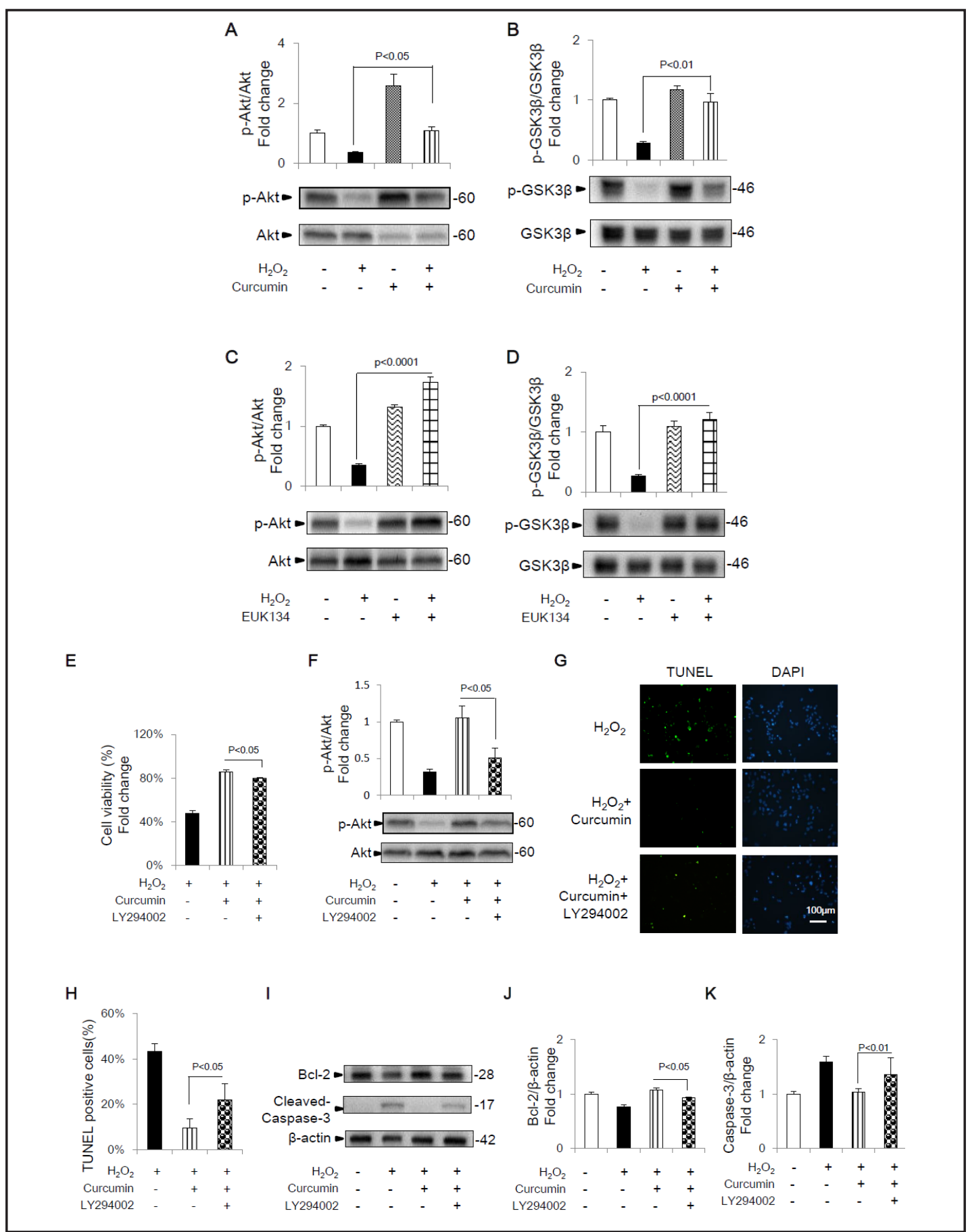

Fig. 5. Curcumin attenuated $\mathrm{H}_{2} \mathrm{O}_{2}$-induced apoptosis in osteoblasts through Akt-GSK3 $\beta$ signaling. Representative immunoblots of p-Akt and Akt (A-C), p-GSK3 $\beta$ and GSK3 $\beta$ (B-D) and relative levels of p-Akt and Akt, p-GSK3 $\beta$ and GSK3 $\beta$ in osteoblasts with $(+)$ or without $(-)$ curcumin/EUK134 treatment in the presence of $\mathrm{H}_{2} \mathrm{O}_{2}(+)$ or culture medium (-). (E) Cell viability determined by MTT reduction in osteoblasts treated with $(+)$ or without (-) curcumin in the presence of $\mathrm{H}_{2} \mathrm{O}_{2}(+)$ or LY294002 (+). Densitometry of immunoreactive bands for p-Akt and Akt (F) in osteoblasts with (+) or without (-) curcumin treatment in the presence of $\mathrm{H}_{2} \mathrm{O}_{2}(+)$ or LY294002 (+).Error bars indicate SEM (n=6). (G) TUNEL staining and (H) assay in the indicated groups. Error bars indicate SEM (n=300). (I) Representative immunoreactive bands for Bcl-2 and Caspsae-3 in in the indicated groups; Quantification of immunoreactive bands for Bcl-2 (J) and Caspsae-3 (K) relative to $\beta$-actin. Error bars indicate SEM $(n=6)$.

\section{KARGER}


Dai et al.: Curcumin Attenuated Osteoblast Apoptosis via Mitochondrial Function and Akt-GSK3 $\beta$ Signaling

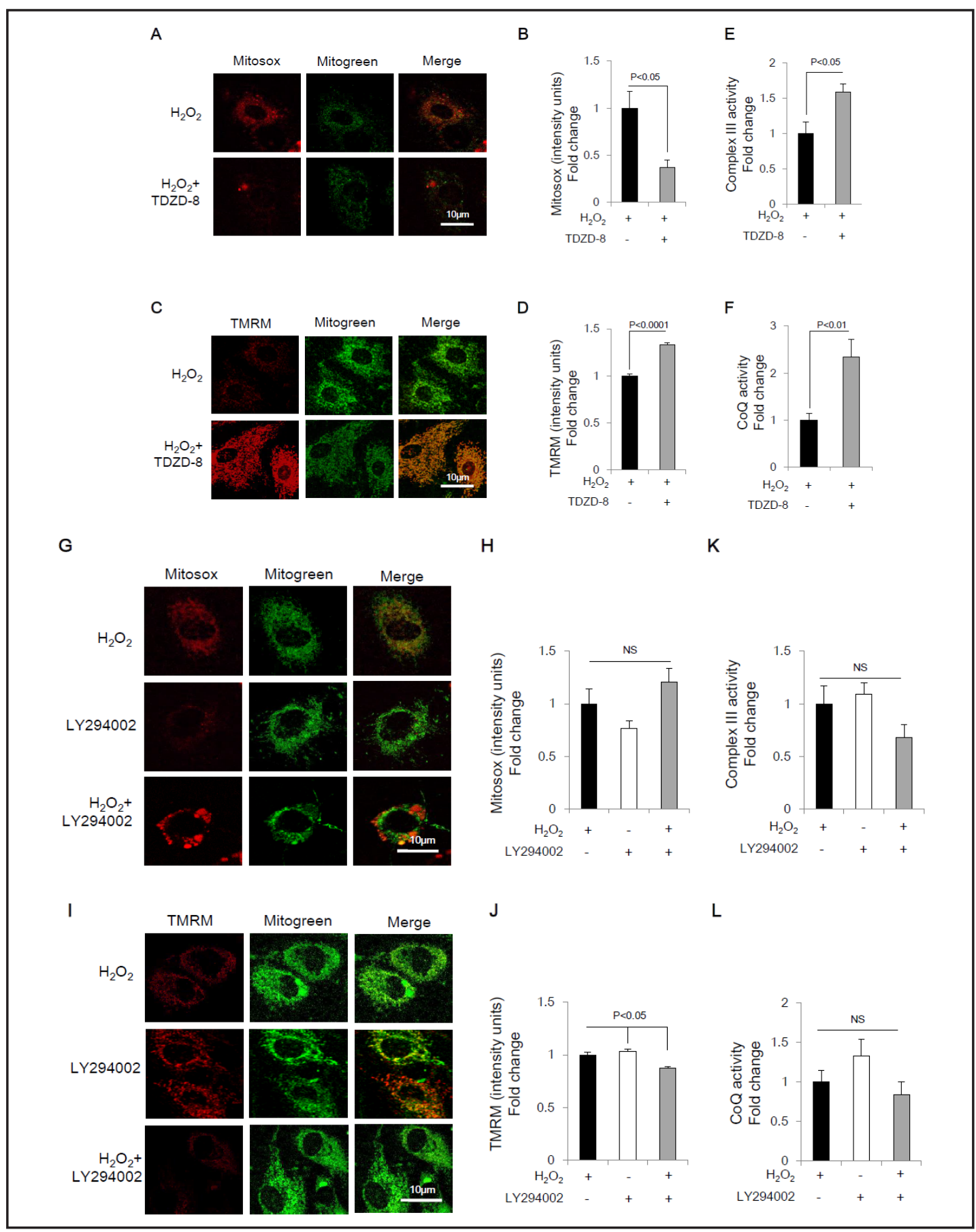

Fig. 6. The relationship between Akt-GSK3 $\beta$ signaling pathway and mitochodnrial dysfunciton in OS induced osteoblast apoptosis. Representative images showing MitoSOX staining (A) and quantification (B) ,TMRM staining (C) and quantification (D) , Complex III activity (E) and CoQ activity (F), in osteoblasts with $(+)$ or without (-) TDZD-8 treatment in the presence of $\mathrm{H}_{2} \mathrm{O}_{2}(+)$. Representative images showing MitoSOX staining (G) and quantification (H) ,TMRM staining (I) and quantification (J), Complex III activity (K) and CoQ activity (L) , in osteoblasts with (+) or without (-) LY294002 treatment in the presence of $\mathrm{H}_{2} \mathrm{O}_{2}(+)$ or culture medium (-).Error bars indicate SEM $(n=15)$.

of $\mathrm{H}_{2} \mathrm{O}_{2}$, a classical generator of $\mathrm{OS}$, significantly decreased osteoblast viability and induced apoptosis. These results demonstrate that $\mathrm{H}_{2} \mathrm{O}_{2}$ exerts a profound cytotoxic effect that 
Dai et al.: Curcumin Attenuated Osteoblast Apoptosis via Mitochondrial Function and Akt-GSK3ß Signaling

reduces osteoblast survival, indicating that it causes defective bone functions. However, curcumin treatment improved cell viability by conferring resistance to apoptosis induced by OS. Furthermore, curcumin promoted osteoblast survival through prevention of OS-induced mitochondrial dysfunction and activation of Akt-GSK3 $\beta$ signaling. Accordingly, our data indicate that curcumin is a beneficial agent to prevent primary or secondary osteoporosis by enhancing osteoblast survival.

Mitochondria are unique and irreplaceable organelles in eukaryotic cells, which not only act as power plants for energy production, but also play important roles in cell death, functions, and survival [40]. In osteoblasts, mitochondria are specialized for calcium transport and involved in calcification of the extracellular matrix [41]. Our previous study demonstrated that pharmaceutical and genetic blockade of dynamic-related protein 1 (Drp1), the primary regulator of mitochondrial fission, significantly protects against $\mathrm{H}_{2} \mathrm{O}_{2}$-induced osteoblast damage, as indicated by increased cell viability, improved mineralization, and restored mitochondrial functions [38]. Therefore, mitochondrial dysfunction in osteoblasts has been both directly and indirectly implicated in osteoporosis. Consistent with our previous findings [38], we observed significant reductions in the mitochondrial membrane potential and respiratory chain complex activity (complex III), while production of mitochondrial ROS was significantly increased in a cell culture model of $\mathrm{H}_{2} \mathrm{O}_{2}$-induced oxidative damage in osteoblasts. Complex III of the mitochondrial respiratory chain might play a major role in ROS production. Inhibition of electron transport causes a collapse of the proton gradient across the mitochondrial inner membrane, thereby decreasing the mitochondrial membrane potential. This effect results in opening of mitochondrial permeability transition pores (mPTPs), the release of proapoptotic proteins into the cytoplasm, and apoptotic cell death [42].

Flow cytometry and TUNEL staining combined with immunoblotting of Bcl-2 and Caspase- 3 showed that $\mathrm{H}_{2} \mathrm{O}_{2}$ caused cell apoptosis in a dose and time-dependent manner in osteoblastic Saos-2 cells. These results were in agreement with a study by Yang et al. [8]. However, investigators from the Kim laboratory have shown that antimycin A induces mitochondrial dysfunction in osteoblasts through suppression of complex IV activity [43]. The discrepancies among these data might be explained by differences in cell types and oxidative stress generators. The Kim group also suggested that antimycin A causes mitochondrial depolarization and ATP depletion that might induce cell necrosis instead of apoptosis. Nonetheless, all these findings strongly support a pivotal role of mitochondrial ROS in mediating mitochondrial dysfunction leading to osteoblast apoptosis during osteoporosis. Furthermore, these observations suggest that novel therapeutic strategies to reduce mitochondrial dysfunction during osteoporosis, such as mitochondria-targeted antioxidants, might significantly prevent development of osteoblast apoptosis in osteoporotic patients.

Curcumin has several pharmacological and biological properties, and evidence has supported its potential protective function in osteoporosis [19-20]. Curcumin might decrease bone resorption by inhibition of osteoclast proliferation, differentiation, and activity as well as by promotion of osteoclast apoptosis [44-47]. Although no consistent conclusion has been reached concerning its benefits in osteogenesis, our present findings demonstrate that curcumin significantly decreases osteoblast apoptosis induced by $\mathrm{H}_{2} \mathrm{O}_{2}$ with similar effectiveness as the antioxidant compound EUK134. The cytoprotective effects of curcumin were caused not only by its antioxidant properties, but also other mechanisms. We found that pretreatment with curcumin significantly attenuated the mitochondrial dysfunction induced by $\mathrm{H}_{2} \mathrm{O}_{2}$, as evidenced by decreased mitochondrial ROS, improved complex III and CoQ activities, and an improved mitochondrial membrane potential. Recent research has revealed that curcumin might have value in prevention and therapy of numerous disorders including neurodegenerative diseases, myocardial ischemia, reperfusion injury, and diabetes. Its potential in all these disorders has been attributed to its effects against mitochondrial dysfunction induced by pathological factors [48]. Conversely, in cancer cells, curcumin induces apoptosis through mitochondrial pathways [49]. Therefore, these previous findings, in combination with our new data, support the conclusion that curcumin alleviates osteoblast 
Dai et al.: Curcumin Attenuated Osteoblast Apoptosis via Mitochondrial Function and Akt-GSK3 $\beta$ Signaling

apoptosis induced by OS through prevention of mitochondrial dysfunction.

Akt is an initiator of downstream pathways that inhibit apoptosis [50]. Moreover, Akt phosphorylates GSK3 $\beta$ to prevent opening of mPTPs, an important master regulator of cell death. Therefore, we examined the Akt-GSK3 $\beta$ signaling pathway to elucidate mechanisms by which curcumin modulates mitochondrial functions and attenuates apoptosis in osteoblasts. We found that curcumin preconditioning significantly enhanced not only phosphorylation of Akt but also that of GSK3 $\beta$ at Ser9. Previous studies have demonstrated that

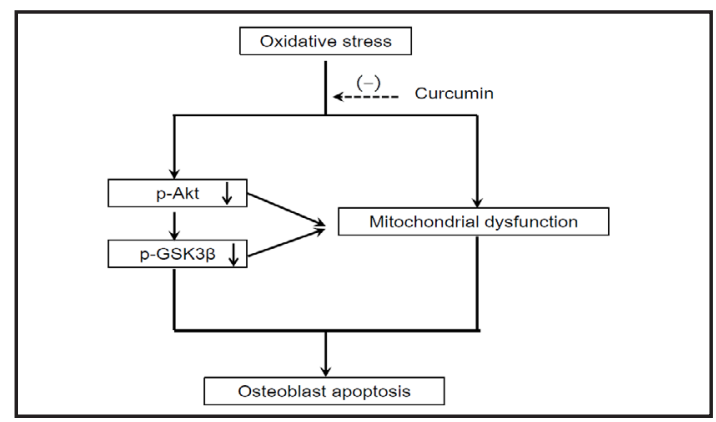

Fig. 7. Working hypothesis: curcumin administration ameliorated oxidative stress-induced apoptosis in osteoblasts through preserving mitochondrial function and activating Akt-GSK3 $\beta$ signaling.

GSK3 $\beta$ phosphorylation at Ser9 leads to interactions with mPTP regulators and inhibits mPTP opening during reperfusion. These effects decrease activation of the cytochrome c-Caspase-3/9 apoptosis pathway, reducing cell apoptosis and protecting hepatic cells from ischemia/reperfusion injury via activation of Akt-GSK3 $\beta$ signaling [51,52].

Our data indicated that blocking PI3K by LY294002, which led to downstream phosphorylation of Akt, amplified $\mathrm{H}_{2} \mathrm{O}_{2}$-induced apoptosis. The anti-apoptotic effect of curcumin was significantly abolished by LY294002, while inhibition of GSK3 $\beta$ significantly suppressed apoptosis induced by $\mathrm{H}_{2} \mathrm{O}_{2}$. Taken together, these data demonstrate that curcumin alleviates osteoblast apoptosis induced by OS through activation of Akt-GSK3 $\beta$ signaling. Furthermore, Akt and GSK3 $\beta$ phosphorylation was associated with mitochondrial dysfunction in OS-induced osteoblast apoptosis. In our previous study [35], mitochondrial abnormalities were induced by imbalanced mitochondrial fusion and fission via a GSK3 $\beta$ Drp1-dependent mechanism. Modulation of the Drp1 pathway or inhibition of GSK3 $\beta$ activity also restores hippocampal long-term potentiation impaired in diabetic mice [35]. Moreover, blockade of Drp1 rescues OS-induced osteoblast dysfunction [38]. Thus, in future studies, investigation of the GSK3 $\beta$-Drp1 pathway should provide more insights into the complex regulation of cell survival and apoptosis of osteoblasts subjected to OS.

In the present study, we used a relatively high concentration of curcumin $(20 \mu \mathrm{M})$ and a short treatment period. No significant adverse effects have been observed in humans who consumed 500-800 mg turmeric powder per day [53]. In long term studies, curcumin administered through diet was safe and showed protective activities. Even very high doses of curcumin ( $8 \mathrm{~g} /$ day) did not cause side effects [54]. However, there is still limited information about the potentially negative effects of curcumin on cell apoptosis and normal cell senescence $[55,56]$. Therefore, further investigation will be needed to explore effective ways to increase curcumin bioavailability.

OS-induced apoptosis of osteoblasts is a complicated process with many aspects of the damage related to survival signaling and mitochondria. Therefore, our experiments addressed only some of the mechanistic pathways involved in this process. Further research will be required to investigate additional mechanisms to modulate the effects of OS on osteoblasts. In addition, we established a $\mathrm{H}_{2} \mathrm{O}_{2}$-induced oxidative cell injury model that has been frequently used in previous studies. $\mathrm{H}_{2} \mathrm{O}_{2}$ functions as both a signaling molecule [57] and cytotoxic agent under pathological conditions. The definite role of $\mathrm{H}_{2} \mathrm{O}_{2}$ in our study needs further exploration.

In conclusion, our study demonstrates that curcumin treatment attenuates OS-induced apoptosis of osteoblasts, possibly through prevention of mitochondrial dysfunction and activation of the Akt-GSK3 $\beta$ signaling pathway (Fig. 7). These findings provide additional evidence for the clinical use of curcumin in prevention or treatment of osteoporosis. 


\section{Cellular Physiology Cell Physiol Biochem 2017;41:661-677 \\ \begin{tabular}{l|l|l}
\hline DOI: 10.1159/000457945 & $\begin{array}{l}\text { C) } 2017 \text { The Author(s). Published by S. Karger AG, Basel } \\
\text { www.karger.com/cpb }\end{array}$ \\
\hline Published Biochemistry
\end{tabular}}

Dai et al.: Curcumin Attenuated Osteoblast Apoptosis via Mitochondrial Function and Akt-GSK3ß Signaling

\section{Acknowledgments}

This work was supported by the Natural Science Foundation of China (81500817 and 81271186), Zhejiang Provincial Natural Science Foundation of China (LY15H140008), Health Science and Technology Project of Zhejiang Province (2016KYB184), Zhejiang Province Public Welfare Project (2017C33081), and Wenzhou Public Technical Research Medical Program (Y20140708 and Y20160051).

\section{Disclosure Statement}

The authors declare no conflict of interest.

\section{References}

1 Zhou Q Zhu L, Zhang D, Li N, Li Q, Dai P, Mao Y, Li X, Ma J, Huang S: Oxidative stress-related biomarkers in postmenopausal osteoporosis: a systematic review and meta-analyses. Dis Markers 2016;2016:7067984.

2 Manolagas SC: From estrogen-centric to aging and oxidative stress: a revised perspective of the pathogenesis of osteoporosis. Endocr Rev 2010;31:266-300.

-3 Moriishi T, Kawai Y, Komori H, Rokutanda S, Eguchi Y, Tsujimoto Y, Asahina I, Komori T: Bcl-2 deficiency activates FoxO through Akt inactivation and accelerates osteoblast differentiation. PLoS One 2014;9:e86629.

4 Zhong ZM, Bai L, Chen JT: Advanced oxidation protein products inhibit proliferation and differentiation of rat osteoblast-like cells via NF-kappaB pathway. Cell Physiol Biochem 2009;24:105-114.

-5 Li M, Zhao L, Liu J, Liu AL, Zeng WS, Luo SQ Bai XC: Hydrogen peroxide induces G2 cell cycle arrest and inhibits cell proliferation in osteoblasts. Anat Rec (Hoboken) 2009;292:1107-1113.

6 Almeida M, Han L, Ambrogini E, Bartell SM, Manolagas SC: Oxidative stress stimulates apoptosis and activates NF-kappaB in osteoblastic cells via a PKCbeta/p66shc signaling cascade: counter regulation by estrogens or androgens. Mol Endocrinol 2010; 24: 2030-2037.

7 Wu Y, Wang D, Wang X, Wang Y, Ren F, Chang D, Chang Z, Jia B: Caspase 3 is activated through caspase 8 instead of caspase 9 during H2O2-induced apoptosis in HeLa cells. Cell Physiol Biochem 2011;27:539-546.

8 Yang YH, Li B, Zheng XF, Chen JW, Chen K, Jiang SD, Jiang LS: Oxidative damage to osteoblasts can be alleviated by early autophagy through the endoplasmic reticulum stress pathway--implications for the treatment of osteoporosis. Free Radic Biol Med 2014;77:10-20.

-9 She F, Wang W, Wang Y, Tang P, Wei J, Chen H, Zhang B: Melatonin protects MG63 osteoblast-like cells from hydrogen peroxide-induced cytotoxicity by maintaining mitochondrial function. Mol Med Rep 2014;9:493498.

10 Bartolomé A, López-Herradón A, Portal-Núñez S, García-Aguilar A, Esbrit P, Benito M, Guillén C: Autophagy impairment aggravates the inhibitory effects of high glucose on osteoblast viability and function. Biochem J 2013;455:329-337.

11 Choi EM, Suh KS, Lee YS: Liquiritigenin restores osteoblast damage through regulating oxidative stress and mitochondrial dysfunction. Phytother Res 2014;28:880-886.

12 Fleenor BS, Sindler AL, Marvi NK, Howell KL, Zigler ML, Yoshizawa M, Seals DR: Curcumin ameliorates arterial dysfunction and oxidative stress with aging. Exp Gerontol 2013;48:269-276.

-13 Morabito R, Falliti G, Geraci A, Spada GL, Marino A: Curcumin protects -SH groups and sulphate transport after oxidative damage in human erythrocytes. Cell Physiol Biochem. 2015;36:345-357.

14 Barzegar A, Moosavi-Movahedi AA: Intracellular ROS protection efficiency and free radical-scavenging activity of curcumin. PLoS One 2011;6:e26012.

15 Hussan F, Ibraheem NG, Kamarudin TA, Shuid AN, Soelaiman IN, Othman F: Curcumin protects against ovariectomy-induced bone changes in rat model. Evid Based Complement Alternat Med 2012;2012:174916.

16 Kim WK, Ke K, Sul OJ, Kim HJ, Kim SH, Lee MH, Kim HJ, Kim SY, Chung HT, Choi HS: Curcumin protects against ovariectomy-induced bone loss and decreases osteoclastogenesis. J Cell Biochem 2011;112:31593166. 


\section{Cellular Physiology Cell Physiol Biochem 2017;41:661-677

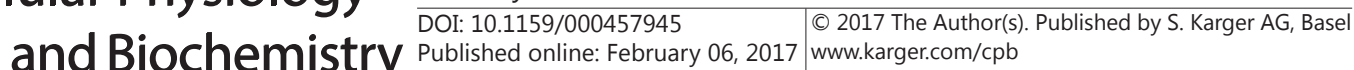

Dai et al.: Curcumin Attenuated Osteoblast Apoptosis via Mitochondrial Function and Akt-GSK3 $\beta$ Signaling

17 French DL, Muir JM, Webber CE: The ovariectomized, mature rat model of postmenopausal osteoporosis: an assessment of the bone sparing effects of curcumin. Phytomedicine 2008;15:1069-1078.

18 Hie M, Yamazaki M, Tsukamoto I: Curcumin suppresses increased bone resorption by inhibiting osteoclastogenesis in rats with streptozotocin-induced diabetes. Eur J Pharmacol 2009;621:1-9.

19 Yang MW, Wang TH, Yan PP, Chu LW, Yu J, Gao ZD, Li YZ, Guo BL: Curcumin improves bone microarchitecture and enhances mineral density in APP/PS1 transgenic mice. Phytomedicine 2011;18:205-213.

20 Xin M, Yang Y, Zhang D, Wang J, Chen S, Zhou D: Attenuation of hind-limb suspension-induced bone loss by curcumin is associated with reduced oxidative stress and increased vitamin D receptor expression. Osteoporos Int 2015;26:2665-2676..

-21 Yang X, He B, Liu P, Yan L, Yang M, Li D: Treatment with curcumin alleviates sublesional bone loss following spinal cord injury in rats. Eur J Pharmacol 2015;765:209-216.

22 Moran JM, Roncero-Martin R, Rodriguez-Velasco FJ, Calderon-Garcia JF, Rey-Sanchez P, Vera V, CanalMacias ML, Pedrera-Zamorano JD: Effects of curcumin on the proliferation and mineralization of human osteoblast-like cells: implications of nitric oxide. Int J Mol Sci 2012;13:16104-16118.

23 Notoya M, Nishimura H, Woo JT, Nagai K, Ishihara Y, Hagiwara H: Curcumin inhibits the proliferation and mineralization of cultured osteoblasts. Eur J Pharmacol 2006;534:55-62.

24 Chan WH, Wu HY, Chang WH: Dosage effects of curcumin on cell death types in a human osteoblast cell line. Food Chem Toxicol 2006;44:1362-1371.

25 Gu Q Cai Y, Huang C, Shi Q, Yang H: Curcumin increases rat mesenchymal stem cell osteoblast differentiation but inhibits adipocyte differentiation. Pharmacogn Mag 2012;8:202-208.

-26 Duan W, Yang Y, Yan J, Yu S, Liu J, Zhou J, Zhang J, Jin Z, Yi D: The effects of curcumin post-treatment against myocardial ischemia and reperfusion by activation of the JAK2/STAT3 signaling pathway. Basic Res Cardiol 2012;107:263.

27 Fiorillo C, Becatti M, Pensalfini A, Cecchi C, Lanzilao L, Donzelli G, Nassi N, Giannini L, Borchi E, Nassi P: Curcumin protects cardiac cells against ischemia-reperfusion injury: effects on oxidative stress, NF-kappaB, and JNK pathways. Free Radic Biol Med 2008;45:839-846.

-28 Huang HC, Xu K, Jiang ZF: Curcumin-mediated neuroprotection against amyloid- $\beta$-induced mitochondrial dysfunction involves the inhibition of GSK-3ß. J Alzheimers Dis 2012;32:981-996.

29 Yang Y, Duan W, Lin Y, Yi W, Liang Z, Yan J, Wang N, Deng C, Zhang S, Li Y, Chen W, Yu S, Yi D, Jin Z: SIRT1 activation by curcumin pretreatment attenuates mitochondrial oxidative damage induced by myocardial ischemia reperfusion injury. Free Radic Biol Med 2013;65:667-679.

30 Leevers SJ, Vanhaesebroeck B, Waterfield MD: Signaling through phosphoinositide 3-kinases: the lipids take centre stage. Curr Opin Cell Biol 1999;11:219-225.

31 Mudher A, Chapman S, Richardson J, Asuni A, Gibb G, Pollard C, Killick R, Iqbal T, Raymond L, Varndell I, Sheppard P, Makoff A, Gower E, Soden PE, Lewis P, Murphy M, Golde TE, Rupniak HT, Anderton BH, Lovestone $\mathrm{S}$ : Disheveled regulates the metabolism of amyloid precursor protein via protein kinase C/ mitogen-activated protein kinase and c-Jun terminal kinase. J Neurosci 2001;21:4987-4995.

-32 Yu W, Zha W, Ke Z, Min Q, Li C, Sun H, Liu C: Curcumin protects neonatal rat cardiomyocytes against high glucose-induced apoptosis via PI3K/Akt signalling pathway. J Diabetes Res 2016;2016:4158591.

33 Hoppe JB, Frozza RL, Pires EN, Meneghetti AB, Salbego C: The curry spice curcumin attenuates betaamyloid- induced toxicity through beta-catenin and PI3K signaling in rat organotypic hippocampal slice culture. Neurol Res 2013;35:857-866.

-34 Gan X, Huang S, Wu L, Wang Y, Hu G, Li G, Zhang H, Yu H, Swerdlow RH, Chen JX, Yan SS: Inhibition of ERKDLP1 signaling and mitochondrial division alleviates mitochondrial dysfunction in Alzheimer's disease cybrid cell. Biochim Biophys Acta 2014;1842:220-231.

35 Huang S, Wang Y, Gan X, Fang D, Zhong C, Wu L, Hu G, Sosunov AA, McKhann GM, Yu H, Yan SS: Drp1mediated mitochondrial abnormalities link to synaptic injury in diabetes model. Diabetes 2015;64:17281742.

-36 Gan X, Wu L, Huang S, Zhong C, Shi H, Li G, Yu H, Howard Swerdlow R, Xi Chen J, Yan SS: Oxidative stressmediated activation of extracellular signal-regulated kinase contributes to mild cognitive impairmentrelated mitochondrial dysfunction. Free Radic Biol Med 2014;75:230-240.

-37 Gan X, Huang S, Yu Q Yu H, Yan SS: Blockade of Drp1 rescues oxidative stress-induced osteoblast dysfunction. Biochem Biophys Res Commun 2015;468:719-725. 


\section{Cellular Physiology Cell Physiol Biochem 2017;41:661-677

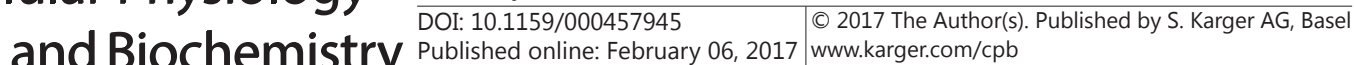

Dai et al.: Curcumin Attenuated Osteoblast Apoptosis via Mitochondrial Function and Akt-GSK3 $\beta$ Signaling

-38 Almeida M, Han L, Bellido T, Manolagas SC, Kousteni S: Wnt proteins prevent apoptosis of both uncommitted osteoblast progenitors and differentiated osteoblasts by beta-catenin-dependent and -independent signaling cascades involving Src/ERK and phosphatidylinositol 3-kinase/AKT. J Biol Chem 2005;280:41342-41351.

-39 Maggio D, Barabani M, Pierandrei M, Polidori MC, Catani M, Mecocci P, Senin U, Pacifici R, Cherubini A: Marked decrease in plasma antioxidants in aged osteoporotic women: results of a cross-sectional study. J Clin Endocrinol Metab 2003;88:1523-1527.

40 Gan X, Huang S, Liu Y, Yan SS, Yu H: The potential role of damage-associated molecular patterns derived from mitochondria in osteocyte apoptosis and bone remodeling. Bone 2014;62:67-68.

41 Stambough JL, Brighton CT, Iannotti JP, Storey BT: Characterization of growth plate mitochondria. J Orthop Res 1984;2:235-246.

42 Balaban RS, Nemoto S, Finkel T. Mitochondia, oxidants, and aging. Cell 2005;120:483-495.

43 Choi EM, Lee YS: Mitochondrial defects and cytotoxicity by antimycin A on cultured osteoblastic MC3T3-E1 cells. Food Chem Toxicol 2011;49:2459-2463.

-44 Moon HJ, Ko WK, Han SW, Kim DS, Hwang YS, Park HK, Kwon IK: Antioxidants, like coenzyme Q10, selenite, and curcumin, inhibited osteoclast differentiation by suppressing reactive oxygen species generation. Biochem Biophys Res Commun 2012;418:247-253.

45 Kim JH, Gupta SC, Park B, Yadav VR, Aggarwal BB: Turmeric (Curcuma longa) inhibits inflammatory nuclear

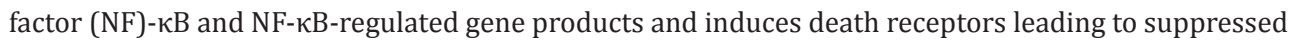
proliferation, induced chemosensitization, and suppressed osteoclastogenesis. Mol Nutr Food Res 2012;56:454-465.

46 Park SK, Oh S, Shin HK, Kim SH, Ham J, Song JS, Lee S: Synthesis of substituted triazolyl curcumin mimics that inhibit RANKL-induced osteoclastogenesis. Bioorg Med Chem Lett 2011;21:3573-3577.

47 Oh S, Kyung TW, Choi HS: Curcumin inhibits osteoclastogenesis by decreasing receptor activator of nuclear factor-kappaB ligand (RANKL) in bone marrow stromal cells. Mol Cells 2008;26:486-489.

-48 Trujillo J, Granados-Castro LF, Zazueta C, Andérica-Romero AC, Chirino YI, Pedraza-Chaverrí J: Mitochondria as a target in the therapeutic properties of curcumin. Arch Pharm (Weinheim) 2014;347:873-884.

49 Cort A, Timur M, Ozdemir E, Ozben T: Effects of curcumin on bleomycin-induced apoptosis in human malignant testicular germ cells. J Physiol Biochem 2013;69:289-296.

-50 Lu Y, Zhou J, Xu C, Lin H, Xiao J, Wang Z, Yang B: JAK/STAT and PI3K/AKT pathways form a mutual transactivation loop and afford resistance to oxidative stress-induced apoptosis in cardiomyocytes. Cell Physiol Biochem 2008;21:305-314.

51 Wanner GA, Ertel W, Müller P, Höfer Y, Leiderer R, Menger MD, Messmer K: Liver ischemia and reperfusion induces a systemic inflammatory response through Kupffer cell activation. Shock 1996;5:34-40.

52 Zhang Q, Fu H, Zhang H, Xu F, Zou Z, Liu M, Wang Q, Miao M, Shi X: Hydrogen sulfide preconditioning protects rat liver against ischemia/reperfusion injury by activating Akt-GSK-3 $\beta$ signaling and inhibiting mitochondrial permeability transition. PLoS One 2013;8:e74422.

53 Chandran B, Goel A: A randomized, pilot study to assess the efficacy and safety of curcumin in patients with active rheumatoid arthritis. Phytother Res 2012;26:1719-1725.

-54 Cheng AL, Hsu CH, Lin JK, Hsu MM, Ho YF, Shen TS, Ko JY, Lin JT, Lin BR, Ming-Shiang W, Yu HS, Jee SH, Chen GS, Chen TM, Chen CA, Lai MK, Pu YS, Pan MH, Wang YJ, Tsai CC, Hsieh CY: Phase I clinical trial of curcumin, a chemopreventive agent, in patients with high-risk or pre-malignant lesions. Anticancer Res 2001;21:2895-2900.

55 Mosieniak G, Adamowicz M, Alster O, Jaskowiak H, Szczepankiewicz AA, Wilczynski GM, Ciechomska IA, Sikora E: Curcumin induces permanent growth arrest of human colon cancer cells: link between senescence and autophagy. Mech Ageing Dev 2012;133:444-455.

56 Grabowska W, Kucharewicz K, Wnuk M, Lewinska A, Suszek M, Przybylska D, Mosieniak G, Sikora E, BielakZmijewska A: Curcumin induces senescence of primary human cells building the vasculature in a DNA damage and ATM-independent manner. Age (Dordr) 2015;37:9744.

-57 Moreno-Loshuertos R, Acín-Pérez R, Fernández-Silva P, Movilla N, Pérez-Martos A, Rodriguez de Cordoba $\mathrm{S}$, Gallardo ME, Enríquez JA: Differences in reactive oxygen species production explain the phenotypes associated with common mouse mitochondrial DNA variants. Nat Genet 2006;38:1261-1268. 